\title{
Ratings checklist for warnings: a prototype tool to aid experts in the adequacy evaluation of proposed or existing warnings
}

\author{
David R. Lenorovitz ${ }^{\mathrm{a} * 1}$, S. David Leonard ${ }^{\mathrm{b}}$, and Edward W. Karnes ${ }^{\mathrm{c}}$ \\ ${ }^{a}$ LENPRO Services, Inc., 3671 S. Huron St, Ste 304, Englewood, CO 80110, USA \\ ${ }^{\mathrm{b}}$ Deparment of Psychology, University of Georgia, Athens, GA 30602-3013, USA \\ ${ }^{\mathrm{c}}$ Edward W. Karnes, LLC, 5843 Willowbrook Dr., Morrison, CO 80465-2238, USA
}

\begin{abstract}
In the field of forensic human factors, experts are often called upon to assess and evaluate the adequacy of new or existing products' warnings or warnings systems. The usual goal of this evaluation is to arrive at a simple binary decision regarding the warning in question (i.e., does it "pass/fail", or is it "adequate/inadequate"). However, such a warning assessment process may in fact be quite complex and multidimensional in its execution. The existing warnings research literature has identified a fairly large number of warnings features or factors likely to have an impact on a given warning's effectiveness or adequacy. The tool addressed in this article is intended for use by a warnings expert (as opposed to one less knowledgeable and informed about complex warnings issues), and can serve as a reminder checklist to help ensure that the expert has taken into consideration the most relevant features or factors during such a warnings adequacy assessment.
\end{abstract}

Keywords: Warnings, Warnings Evaluations, Warning Adequacy, Product Safety

\section{Introduction}

Within the discipline of forensic human factors, a considerable amount of attention is directed toward the topic areas of hazard warnings and/or warning systems. Principal activities in these areas include devising and configuring new warnings, evaluating and assessing existing warnings, testing the efficacy of proposed warnings (in terms of how well their meanings are understood, and their likelihood of impacting subsequent behavior), and generally judging the adequacy of a warning in meeting its overall objectives of alerting a user about a given hazard, identifying the consequences associated with that hazard, and advising the user as to how to avoid becoming a victim of that hazard.

\footnotetext{
*E-mail: lenproservices@qwest.net
}

It has been recommended, Laughery [22], that these types of warnings design, development, testing, and evaluation processes be carried out by "warnings experts". Briefly, a warnings expert is someone who (a) is familiar with the body of warnings research literature that has developed over the past three decades; (b) has some expertise in relevant methodologies such as hazard analysis, fault-tree and failuremodes analyses, task analysis, display design, and data collection and analysis; and (c) has a level of knowledge about human cognition - how people process information.

That body of warnings research literature is quite large, and is continually growing. And, the warnings adequacy evaluation process can be, and often is, quite complex and uniquely specific to each hazard analysis or product safety assessment situation en- 
countered. The various warnings features or factors that have been described and discussed in the literature may be more or less applicable in each such instance. And, the warnings expert must decide, on a case by case basis, which of these factors is most relevant.

In a recent article, Lenorovitz, Karnes, \& Leonard [26], presented case study examples of how a warnings adequacy assessment process might be conducted, and which of a set of warnings evaluation features were judged to be most applicable within each case considered. Several reviewers of that article suggested that there might be some value in compiling a kind of warning expert's reminder checklist from that set of identified warnings adequacy characteristics. Such a checklist ought to be of use to warnings experts engaged in a given warnings adequacy assessment task - to help remind them of items that might be particularly relevant, and/or to help organize and justify their thinking about how or why they view a given warning as being adequate. That was the motivation for the current exercise, and the basis upon which the following prototype version of a checklist tool is offered.

\section{Developing the checklist tool}

It was decided that the tool would initially be configured as a matrix having 15 rows and 7 columns. Table 1 depicts this structure. Each of the "main" rows represents one of the 15 features that were originally identified in the Lenorovitz, et al. [26] paper. Subsequently, it was decided that the fourth row, "Conformity with Standards and Other Recommended Practices", was overly-broad, and four additional "sub-rows" ("Color Coding", Safety Alert Symbols", "Signal Words", and "Message") were then added.

The seven column headings consist of the following: (a) a feature-identifying index or reference number, (b) the name or descriptive title of the feature (c) a brief definition or description of the feature, (d) one or more literature citations - i.e., references to source documents where further information can be found regarding that feature - and, the $5^{\text {th }}, 6^{\text {th }}, \& 7^{\text {th }}$ columns provide a place where a warnings expert can enter a ratings checkmark to indicate whether he/she judged that particular aspect of the subject warning to have been handled in a "deficient", "adequate", or "outstanding" manner.

Several additional points should be noted with respect to this table. The first is that the current au- thors thought that this set of features represented a key grouping of some of the most salient features or factors in determining the adequacy of many different types of warnings. They did not conclude that these were the only factors worth considering. Nor, did they conclude that they were the most significant or most important factors in all warnings evaluation situations. Any warnings expert who elects to use this tool is encouraged to add or omit features/factors in order to adapt or tailor the checklist to the particular warning situation with which he/she is dealing..

Second, the authors selected this particular set of features because they thought that these features were well represented within the warnings literature, and that they had been cited, researched, described and discussed by numerous other warnings experts over a lengthy period of time. If you will, they thought that these features collectively represented a group of highly regarded, "consensus" picks - ones that most other warnings experts will at least recognize as ones with which they are already familiar and comfortable.

Third, the authors gave considerable thought to the source references they chose to list in column four. It would be easy to identify as many as $12-20$ plausible citations for each of these factors. While trying to adhere to some pretty severe (self-imposed) space limitations, the authors merely wanted to select a small set of representative references - again, ones with which most warnings experts were likely to be familiar, could fairly easily access, and from which they might be able to acquire additional, useful information.

Fourth, it is worth noting that this tool has been described as a "prototype", or early-generation tool. It is anticipated that there will be numerous comments and suggestions about the benefits and deficiencies of the tool, and feedback from those who take the time to "try it out", as to how to improve both its appearance and function. That is a very likely outcome - one that is expected, intended, and will be greatly appreciated. Our experience has been that warnings experts are typically not shy about expressing their opinions.

\section{Using the checklist tool}

As stated previously, this tool was developed with warnings experts in mind - i.e., foreseeing that such 


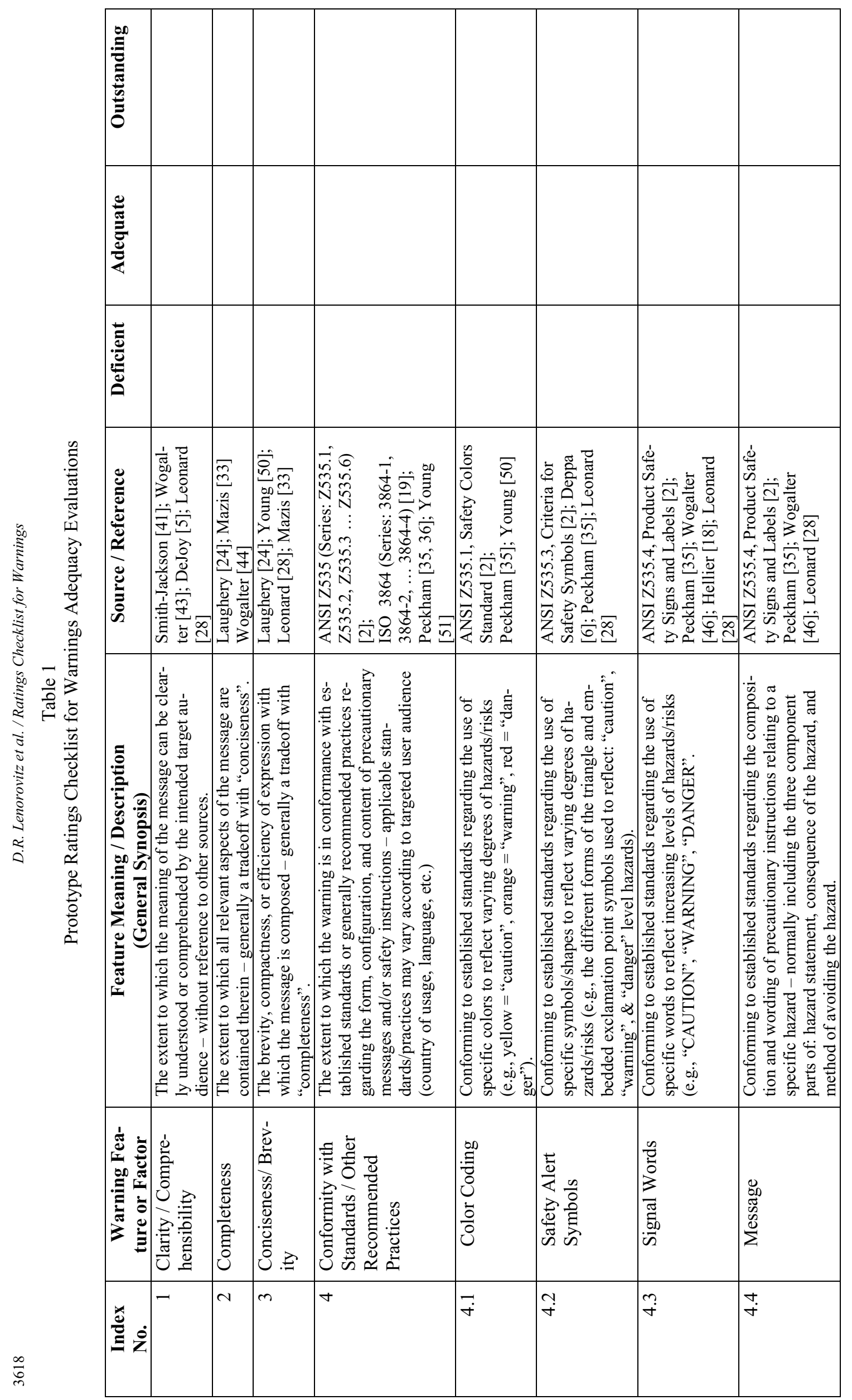




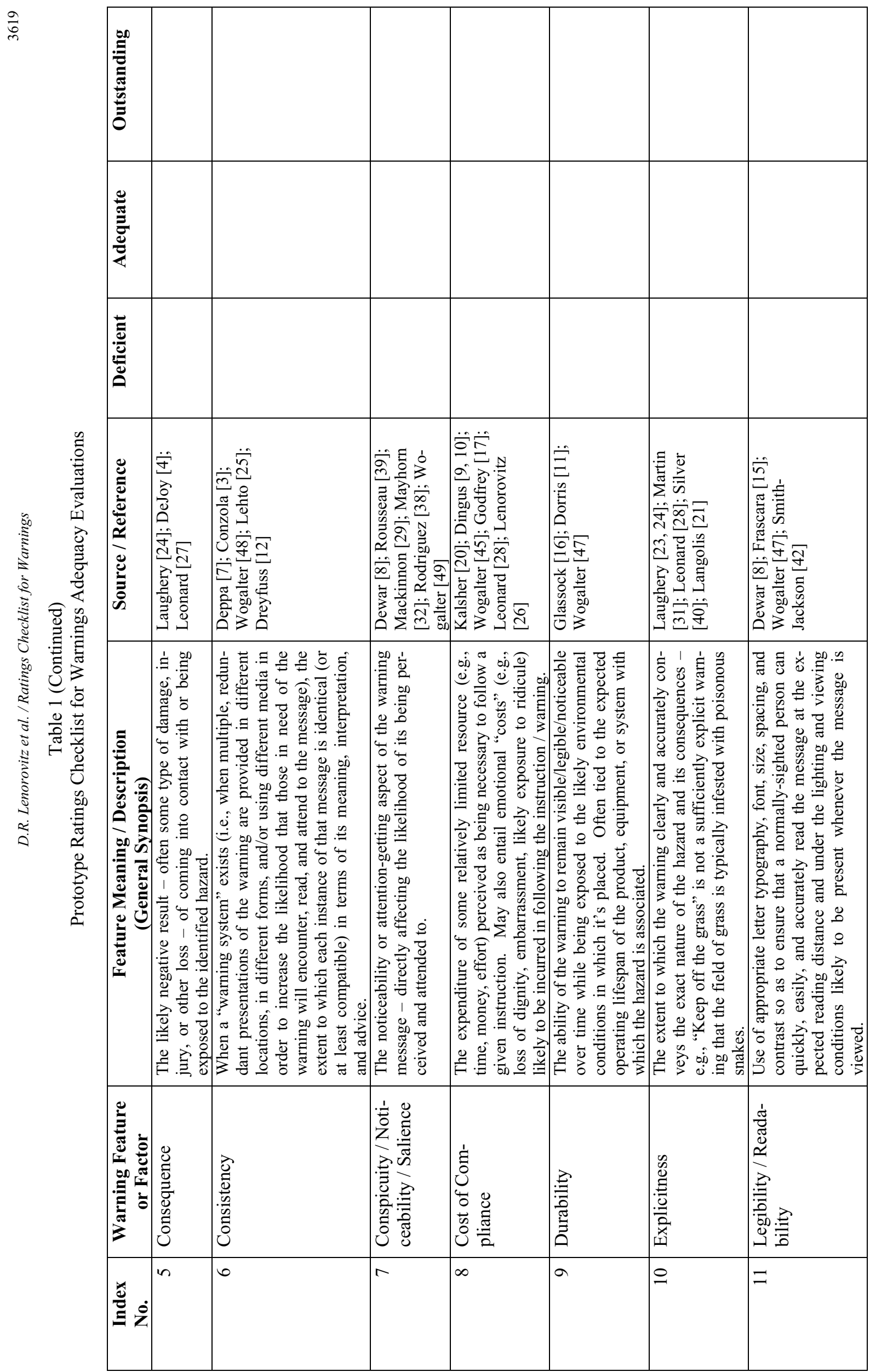




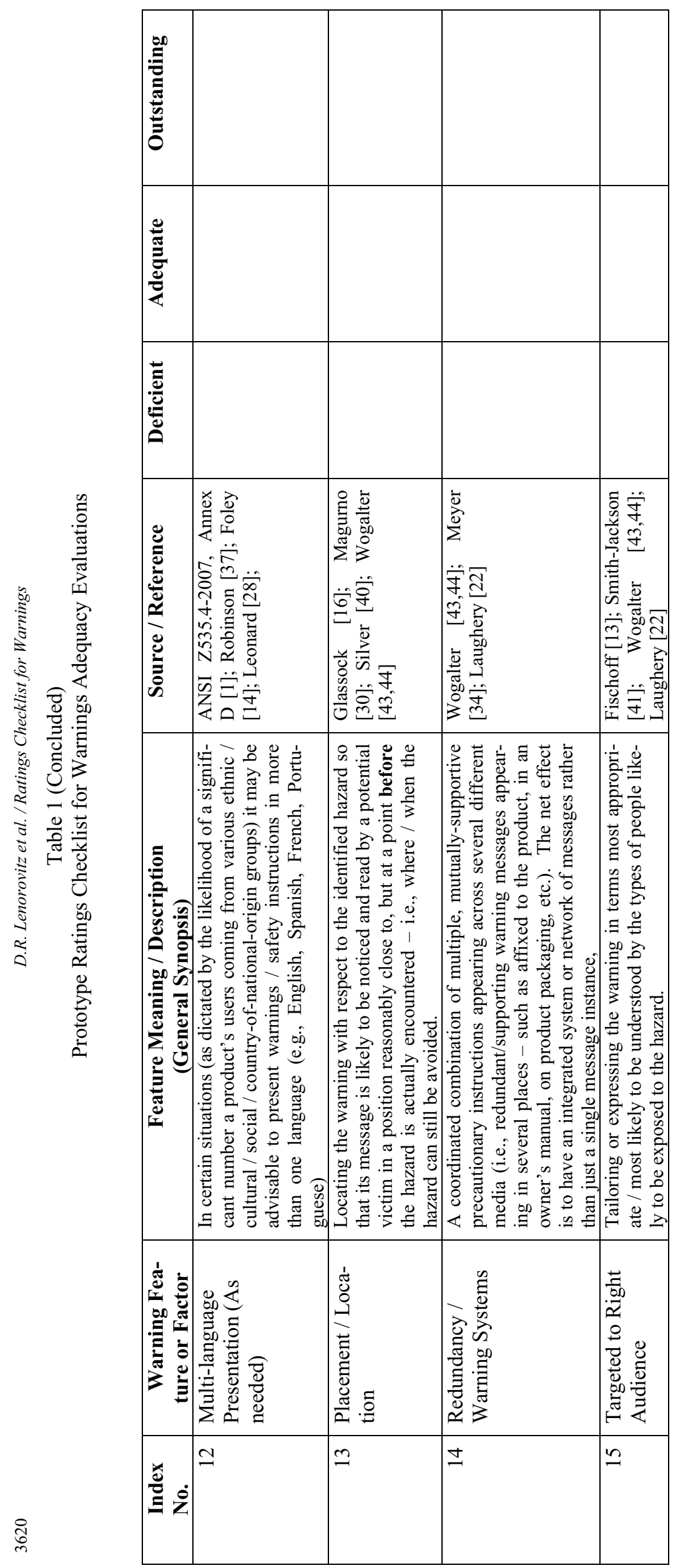


experts would be its intended user population.

It was not envisioned that this tool would be suitable for novices, nor was it expected that the tool would somehow instantly bestow "warning expert status" upon whoever tried to use it. Instead, it is assumed that this type of expertise is something that the user of the tool would bring to the arena $\mathrm{him} /$ herself. That is, perhaps the tool should come with its own set of precautionary instructions, (e.g., "Do not try to use this at home. This tool should only be used by professionals already familiar with and knowledgeable about warnings.")

It should also be noted that warnings experts often are retained by attorneys who are representing clients in civil lawsuits. When warnings experts are called upon to testify in such litigation, and their credentials and standing have been recognized and accepted by the court, they become expert witnesses.

It is entirely possible for one warnings expert to have been retained by the attorney representing the plaintiff to testify on his/her behalf, and another warnings expert to have been retained by the attorney representing the defendant(s) to testify on their behalf. And, when the case involves differing views regarding the warnings issues involved - i.e., often with the plaintiff's side claiming that a warning was needed, but none was provided, or that the one that was provided was inadequate; while the defendants' side may be claiming that no warnings were needed, or that the one that was provided was entirely adequate for its purpose. In such situations a checklist tool such as this might prove to be of value to the warnings experts offering opinions on behalf of either party.

Both of these types of experts need to be able to substantiate and defend their respective opinions. And, this kind of a tool can be helpful to organize their thoughts and to better convey the logical reasons why / how either of them arrived at their respective conclusions.

It would seem likely that this kind of a scenario would give rise to the need to make use of the information contained in the fourth column of the table. This reference information may be particularly useful to perform additional background research, and to see if one or more of the original literature sources identified therein might contain additional information, data, or conclusions directly relevant to the specific point they are trying to make.

Here, it is worth pointing out that the space constraints of the table dictated that the references provided in that fourth column appear in a somewhat abbreviated form. Many papers, articles, and books are prepared and submitted by multiple authors. However, the fourth column of the table lists only a single author for each citation. The interested reader will note that full citations for each such reference (including the complete listing of each co-authors' name; the publisher of the book, journal, or periodical in which it appeared, and the relevant page numbers) are provided in the References section that appears at the end of this article.

Finally, some comment is warranted about the final three columns in the table - where the warnings expert is encouraged to place a checkmark in one of the three rating columns labeled: "Deficient", "Adequate", or "Outstanding". There is nothing sacred about this particular type of three-point scale, or set of rating categories. A given warnings expert should feel free to use a 10-point, "bad" to "good" rating scale, a binary, "go"/"no-go" or "pass"/"fail" rating system, or whatever rating system best fits that expert's mental model or adequacy evaluation scheme. These authors simply suggested this particular three-category scale, because it seemed to represent the right level of resolution or degree of granularity for the decisions being made, and because of the ease with which one can simply and quickly scan down the rating columns, note where the checkmarks fall, and thereby gain a quick visual impression of the overall quality level of the subject warning. If there are a lot of checkmarks piled up on the left ("deficient") side of that part of the table, it would seem to justify a rather poor overall assessment of the warning, and/or it could help to quickly pin-point the particular warning features or factors most in need of further attention or improvement.

\section{Summary / Conclusions}

This article described a prototype warnings feature checklist - one intended to help experts in their evaluations or assessments of a given warning system design or implementation. In a manner not unlike a preprinted grocery shopping item checklist, it presents and reminds one of a relatively small set of commonly needed items - ones that experience may have shown to be frequently relevant or appropriate, but that could well be overlooked at one time or another. The checklist tool was configured with a flexible and adaptable set of user needs in mind, but at the same time was intended to compactly present a core group of warning characteristics and key 
areas of concern. The authors are convinced that such a relatively simple, but informative tool ought to be of value to its intended users - not only in conducting their uniquely individual warnings analysis processes, but also in their efforts to better organize their thoughts and more clearly convey their resulting conclusions and opinions to those in need of hearing and understanding them.

\section{References}

[1] American National Standards Institute. ANSI Z535.4-2007; Product Safety Signs and Labels, Annex D: Translation of Signal Words. (29 different languages).

[2] American National Standards Institute. ANSI Z535.1, Safety Colors Standard; ANSI Z535.2, Environmental and Facility Safety Signs; ANSI Z535.3, Criteria for Safety Symbols; ANSI Z535.4, Product Safety Signs and Labels; ANSI Z535.5, Safety Tags and Barricade Tapes; ANSI Z535.6, Product Safety Information in Product Manuals, Instructions, and Other Collateral Materials. Various ANSI Z53 Series versions / updates have been released in 1991, 1998, 2002, 2007, and 2011. New York: ANSI.

[3] Conzola, V.C. and Wogalter, M. S. (1998). Discrimination among sign and label warning signal words. Human Factors and Ergonomics in Manufacturing, 8:4, 289-301.

[4] DeJoy, D.M. (1999) Motivation. In: Wogalter, M.S., DeJoy, D.M., \& Laughery, K.R. (Eds.) Warnings and Risk Communication. (pp 225-231) Philadelphia, PA: Taylor \& Francis.

[5] DeJoy, D.M. \& Brooks, K. L. (2001) Designing effective warning messages for patient medication information. In: Wogalter, M.S., Young, S.L., \& Laughery, K.R., Sr. (Eds.) Human Factors Perspectives on Warnings, Volume 2. (pp 61-62) Santa Monica, CA: The Human Factors and Ergonomics Society.

[6] Deppa, S.W. \& Martin, B.J. (2001) Human factors behind the improved ANSI Z535.3 label standard for safety symbols. In: Wogalter, M.S., Young, S.L., \& Laughery, K.R., Sr. (Eds.) Human Factors Perspectives on Warnings, Volume 2. (pp 68-72) Santa Monica, CA: The Human Factors and Ergonomics Society.

[7] Deppa, S.W, (2006). U.S. and international standards for safety symbols. In: Wogalter, M.S., (Ed.) Handbook of Warnings. (pp 477-486) Mahwah, NJ: Lawrence Erlbaum Associates.

[8] Dewar, R.E. (2006) Road warnings with traffic control devices. In: Wogalter, M.S., (Ed.) Handbook of Warnings. (pp 178-179) Mahwah, NJ: Lawrence Erlbaum Associates.

[9] Dingus, T.A., Hunn, B.P., \& Wreggit, S.S. (1991a). A most critical warning variable: Two demonstrations of the powerful effects of cost on warning compliance. In: Proceedings of the Human Factors Society 35th Annual Meeting (pp 10341038). Santa Monica, California: Human Factors Society.

[10]Dingus, T.A., Hunn, B.P., \& Wreggit, S.S. (1991b). Two reasons for providing protective equipment as part of hazardous consumer product packaging. In: Proceedings of the Human Factors Society 35th Annual Meeting (pp 1039-1042). Santa Monica, California: Human Factors Society.

[11] Dorris, N.T. and Davis J. (2003). Testing and comprehensibility of warnings. In: Proceedings of the Human Factors and Ergonomics Society $47^{\text {th }}$ Annual Meeting (pp 1726-1729), Santa Monica, CA: Human Factors and Ergonomics Society.
[12]Dreyfuss, H., \& Clifton, P., (1970). Visual communication: A study of symbols. Graphic Science, April, 21-26.

[13]Fischoff, B. \& Eggers, S. (2006) Mental models of warning decisions: Identifying and addressing information needs. In: Wogalter, M.S., (Ed.) Handbook of Warnings. (pp 279-287) Mahwah, NJ: Lawrence Erlbaum Associates.

[14]Foley. J.P. (2006) Regulatory requirements for motor vehicle warnings. In: Wogalter, M.S., (Ed.) Handbook of Warnings. (p 558) Mahwah, NJ: Lawrence Erlbaum Associates.

[15] Frascara, J. (2006) Typography and the visual design of warnings. In: Wogalter, M.S., (Ed.) Handbook of Warnings. (pp 391-399) Mahwah, NJ: Lawrence Erlbaum Associates.

[16] Glassock, N.F. and Dorris, N.T. (2006). Warning degradation and durability. In: Wogalter, M.S., (Ed.) Handbook of Warnings. (pp 499-528) Mahwah, NJ: Lawrence Erlbaum Associates.

[17] Godfrey, S.S., Rothstein, P.R., \& Laughery, K.R. (1985) Warnings: Do they make a difference? In: Proceedings of the Human Factors Society 29th Annual Meeting (pp 669-673). Santa Monica, California: Human Factors Society.

[18]Hellier, E. \& Edworthy, J. (2006) Signal words. In: Wogalter, M.S., (Ed.) Handbook of Warnings. (pp 407-427) Mahwah, NJ: Lawrence Erlbaum Associates.

[19] International Organization for Standardization. ISO 38641:2011, Graphical symbols - safety colours and safety signs - Part 1: Design principles for safety signs and safety markings; ISO 3864-2:2004, Graphical symbols - safety colours and safety signs - Part 2: Design principles for product safety labels; ISO 3864-3:2006, Graphical symbols - safety colours and safety signs - Part 3: Design principals for graphical symbols for use in safety signs; ISO 3864-4:2011, Graphical symbols - safety colours and safety signs - Part 4: Colorimetric and photometric properties of safety sign materials. Geneva: ISO.

[20]Kalsher, J.M. \& Williams, K.J. (2006). Behavioral compliance: Theory, methodology, and results. In: Wogalter, M.S., (Ed.) Handbook of Warnings. (313-331) Mahwah, NJ: Lawrence Erlbaum Associates.

[21]Langlois, L.A., Wallen, B.A., Teret, S.P., Bailey, L.A., Hershey, J.H., \& Peeler, M.O. (1991). The impact of specific toy warning labels. In: The Journal of the American Medical Association 265:21, 2848-2856.

[22]Laughery, K.R. (1999) The expert witness. In: Wogalter, M.S., DeJoy, D.M., \& Laughery, K.R. (Eds.) Warnings and Risk Communication. (pp 331- 336) Philadelphia, PA: Taylor $\&$ Francis.

[23] Laughery, K.R. \& Hammond, A. (1999) Overview. In: Wogalter, M.S., DeJoy, D.M., \& Laughery, K.R. (Eds.) Warnings and Risk Communication. (pp 9- 11) Philadelphia, PA: Taylor \& Francis.

[24]Laughery, K.R., Sr., \& Smith, D.P. (2006) Explicit information in warnings. In: Wogalter, M.S., (Ed.) Handbook of Warnings. (pp 419-428) Mahwah, NJ: Lawrence Erlbaum Associates.

[25]Lehto, M. R., \& Miller, J.M. (1986). Warnings, Volume I: Fundamentals, Design, Evaluation, and Methodologies. Ann Arbor, MI: Fuller Technical Publications.

[26]Lenorovitz, D.R., Karnes, E.W., \& Leonard, S.D. (In Press) Mitigating product hazards via user warnings alone: When/why "warnings-only" approaches are likely to fail. In: Human Factors and Ergonomics in Manufacturing \& Service Industries. Hoboken, NJ: Wiley-Blackwell.

[27]Leonard, S.D., Mathews, D., \& Karnes, E.W. (1994) How does the population interpret warning signals? In: Laughery, K.R., Sr., Wogalter, M.S., \& Young, S.L. (Eds.) Human Fac- 
tors Perspectives on Warnings. (pp 140-144) Santa Monica, CA: The Human Factors and Ergonomics Society.

[28]Leonard, S.D., Otani, H., \& Wogalter, M.S. (1999) Comprehension and memory. In: Wogalter, M.S., DeJoy, D.M., \& Laughery, K.R. (Eds.) Warnings and Risk Communication. (pp 149-183) Philadelphia, PA: Taylor \& Francis.

[29] Mackinnon, D.P. \& Nohre, L. (2006) Alcohol and tobacco warnings. In: Wogalter, M.S., (Ed.) Handbook of Warnings. (pp 673-674) Mahwah, NJ: Lawrence Erlbaum Associates.

[30] Magurno, A.B. \& Wogalter, M.S. (2001) Behavioral compliance with warnings: Effects of stress and placement. In: Wogalter, M.S., Young, S.L., \& Laughery, K.R., Sr. (Eds.) Human Factors Perspectives on Warnings, Volume 2. (pp 159-163) Santa Monica, CA: The Human Factors and Ergonomics Society.

[31] Martin, B. J. (2000). The value of explicit hazard and consequence warnings for products with hidden hazards. In: Proceedings of the Human Factors and Ergonomics Society 44th Annual Meeting (pp. 4.302-4.305). Santa Monica, CA: Human Factors and Ergonomics Society.

[32] Mayhorn, C.B. \& Podany, K.I. (2006) Warnings and aging: Describing the receiver characteristics of older adults. In: Wogalter, M.S., (Ed.) Handbook of Warnings. (pp 356-357) Mahwah, NJ: Lawrence Erlbaum Associates.

[33] Mazis, M.B. \& Morris, L.A. (1999) Channel. In: Wogalter, M.S., DeJoy, D.M., \& Laughery, K.R. (Eds.) Warnings and Risk Communication. (pp 110-111) Philadelphia, PA: Taylor \& Francis.

[34] Meyer, J. (2006) Responses to dynamic warnings. In: Wogalter, M.S., (Ed.) Handbook of Warnings. (pp 221-222) Mahwah, NJ: Lawrence Erlbaum Associates.

[35]Peckham, G.M. (2006a) An overview of the ANSI Z535 standards for safety signs, labels, and tags. In: Wogalter, M.S., (Ed.) Handbook of Warnings. (pp 437-443) Mahwah, NJ: Lawrence Erlbaum Associates.

[36]Peckham, G.M. (2006b) ISO design standards for safety signs and labels. In: Wogalter, M.S., (Ed.) Handbook of Warnings. (pp 455-462) Mahwah, NJ: Lawrence Erlbaum Associates.

[37] Robinson, P.A. (2009) Writing and Designing Manuals and Warnings, 4th Ed. (pp 209-228) Boca Raton, FL: CRC Press.

[38] Rodriquez, M.A. (1991) What makes a warning label salient? In: Proceedings of the Human Factors Society 35th Annual Meeting (pp 1029-1033). Santa Monica, California: Human Factors Society.

[39] Rousseau, G.K. \& Wogalter. M.S. (2006) Research on warning signs. In: Wogalter, M.S., (Ed.) Handbook of Warnings. (pp 149-150) Mahwah, NJ: Lawrence Erlbaum Associates.

[40] Silver, N.C. \& Braun, C.C. (1999) Behavior. In: Wogalter, M.S., DeJoy, D.M., \& Laughery, K.R. (Eds.) Warnings and Risk Communication. (pp 249- 250) Philadelphia, PA: Taylor \& Francis.

[41] Smith-Jackson, T. (2006) Receiver characteristics. In: Wogalter, M.S., (Ed.) Handbook of Warnings. (pp 335-343) Mahwah, NJ: Lawrence Erlbaum Associates.

[42] Smith-Jackson, T.L. \& Wogalter, M.S. (2006) Methods and procedures in warning research. In: Wogalter, M.S., (Ed.) Handbook of Warnings. (pp 27-29) Mahwah, NJ: Lawrence Erlbaum Associates.

[43] Wogalter, M.S. (2006a) Scope of warnings. In: Wogalter, M.S., (Ed.) Handbook of Warnings. (pp 5-8) Mahwah, NJ: Lawrence Erlbaum Associates.

[44] Wogalter, M.S. (2006b) Communication-human information processing (C-HIP) model. In: Wogalter, M.S., (Ed.) Handbook of Warnings. (pp 51-61) Mahwah, NJ: Lawrence Erlbaum Associates.
[45] Wogalter, M.S., Allison, S.T. \& McKenna, N.A. (1989). Effects of cost and social influence on warning compliance. Human Factors, 31,133-140.

[46] Wogalter, M.S., Conzola, V.C., \& Vigilante, W.J., Jr. (2006) Applying usability engineering principles to the design and testing of warning text. In: Wogalter, M.S., (Ed.) Handbook of Warnings. (p 489) Mahwah, NJ: Lawrence Erlbaum Associates.

[47] Wogalter, M.S. \& Leonard, S.D. (1999) Attention capture and maintenance. In: Wogalter, M.S., DeJoy, D.M., \& Laughery, K.R. (Eds.) Warnings and Risk Communication. (pp 131-135) Philadelphia, PA: Taylor \& Francis.

[48] Wogalter, M. S. and Silver, N. C. (1990). Arousal strength of signal words. Forensic Reports, 3, Hemisphere Publishing Corporation

[49] Wogalter, M.S. \& Vigilante, W.J., Jr. (2006) Attention switch and maintenance. In: Wogalter, M.S., (Ed.) Handbook of Warnings. (pp 249-250) Mahwah, NJ: Lawrence Erlbaum Associates.

[50] Young, S.L., Frantz, J.P., Rhoades, T.P., \& Hall, S.M. (2006) Development and objectives of the ANSI Z535 series of standards for safety signs and colors: A historical perspective. In: Wogalter, M.S., (Ed.) Handbook of Warnings. (pp 445-462) Mahwah, NJ: Lawrence Erlbaum Associates.

[51] Young, S.L., \& Lovvoll, D.R. (1999) Intermediate processing stages: Methodological considerations for research on warnings. In Wogalter, M.S., DeJoy, D.M., \& Laughery, K.R. (Eds.) Warnings and Risk Communication. (pp 35-36) Philadelphia, PA: Taylor \& Francis. 